\title{
Erythema Dyschromicum Perstans: Identical to Ashy Dermatosis or Not?
}

\author{
Takafumi Numata Kazutoshi Harada Ryoji Tsuboi \\ Yoshihiko Mitsuhashi \\ Department of Dermatology, Tokyo Medical University, Tokyo, Japan
}

\section{Key Words}

Pigmented skin lesions - Erythema dyschromicum perstans · Ashy dermatosis · Dermatosis cenicienta $\cdot$ Lichenoid tissue reaction

\begin{abstract}
Erythema dyschromicum perstans (EDP) and ashy dermatosis (AD) are pigmentary disorders of unknown etiology. EDP is usually considered to be identical to $A D$; however, a new clinical classification for EDP was proposed in the recent literature. Herein, we report a typical case of EDP observed in an African-American man. Interestingly, the late skin lesions in this case fit the criteria of $A D$ as well. While there appear to be a few clinical cases that can be diagnosed as both EDP and AD based on the clinical course, the preponderance of the evidence in the published reports of EDP and $A D$ and the clinical findings reported here strongly suggest that they are two distinct entities in terms of the extent of the inflammation, albeit on the same spectrum of pigment disorders.

(c) 2015 S. Karger AG, Basel
\end{abstract}

\section{Introduction}

Erythema dyschromicum perstans (EDP) is a pigmentary disorder characterized by multiple pigmented macules on the trunk and proximal extremities [1-3]. The hallmark of this disease is erythema occurring on the border of the pigmented macules. On the other hand, ashy dermatosis (AD) or dermatosis cenicienta is a pigmented condition characterized by persistent ashy hypermelanosis [4,5]. Although these diseases are often considered to be identical, some clinical features differ [6]. For example, erythema with scaling around the pigmented patch is a characteristic feature of EDP [3]. However, a recent report demonstrated that the erythematous halo was associated with only $17.3 \%$ of EDP cases [7]. Moreover, a 
Numata et al.: Erythema Dyschromicum Perstans: Identical to Ashy Dermatosis or Not?

new clinical classification for EDP has been proposed in the recent literature [8]. Herein, we report a typical case of EDP, in which the late skin lesions could be construed as a symptom of $\mathrm{AD}$, and discuss the difference between these two diseases.

\section{Case Report}

A 61-year-old African-American man presented with a 10-year history of erythema, pigmented macules, and patches on the trunk and extremities. The erythema gradually turned into pigmented macules, which continued to increase in number over time. The macules typically darkened and were sometimes accompanied by pruritis.

The patient visited our clinic complaining of skin eruptions. He was not using any prescription or over-the-counter drugs at the time. A physical examination revealed brownishgrey to greyish-black pigmented macules and patches on the trunk and extremities. The 1- to 3 -cm oval macules appeared in a Christmas-tree pattern on his back. Some of macules were surrounded by an erythematous halo and had slightly elevated borders. The margins of the macules were relatively clearly demarcated, and some of the lesions were associated with scales (fig. 1a) and also often with mild pruritis. Darier's sign was negative. No other skin, mucous membrane, nail, or hair abnormalities were observed in this patient. The laboratory tests including peripheral blood count and biochemistry were all within normal limits. A skin biopsy specimen from the pigmented macules on the right thigh revealed hyperkeratosis and parakeratosis in the stratum corneum and focal infiltration of lymphocytes in the epidermis. Melanin incontinence and perivascular lymphocytic infiltration in the upper dermis were observed (fig. 2). These findings implied the previous occurrence of a lichenoid tissue reaction.

Observation of the characteristic pigmented macules associated with an erythematous halo with overlying scales led to the diagnosis of EDP. A topical steroid eliminated the erythematous halo, and an oral antihistamine reduced the itching. After a 4-month follow-up, a dermatological examination revealed pigmented macules and patches on the trunk and the proximal extremities. The color of the macules and patches ranged from brownish-grey to grey. The eruptions were flat and without infiltration or erythematous halos. These hallmark clinical features led to the diagnosis of AD. Four years after the diagnosis, some skin lesions have disappeared while new pigmented macules and patches have developed (fig. 1b). During the follow-up, no erythematous halos were observed.

\section{Discussion}

EDP was first described by dermatologists in Venezuela in 1961. This rare inflammatory skin disorder is characterized by asymptomatic, slowly progressing, ashy-gray, macular hyperpigmentation of the skin [1]. The expanding macules have a slightly raised, erythematous border in the initial inflammatory stage. In the pigmentary stage, macules in various shades of gray are observed mainly on the trunk, limbs, and face.

Ramirez [4], a dermatologist in El Salvador, first reported in 1957 what he described as a novel pigmentary disorder characterized by an eruptive, asymptomatic rash consisting of ash-colored macules. This disease was named $\mathrm{AD}$, or dermatosis cenicienta, and recognized as a well-defined clinical entity. Although some standard dermatology textbooks state that EDP is identical to $\mathrm{AD}[5,6]$, some cases of EDP without the erythematous halo, a major manifestation of EDP, have been reported [9]. Furthermore, Chang et al. [7] observed that the 
Numata et al.: Erythema Dyschromicum Perstans: Identical to Ashy Dermatosis or Not?

peripheral erythematous borders were observed only in 12/68 (17.6\%) patients with EDP. These reports demonstrate that EDP can occur without the erythematous halo. Inoue et al. [10] postulated that only cases with marginal erythema should be considered as EDP, while Zaynoun et al. [8] recently proposed a novel, separate classification for EDP and AD.

The existence of erythema around the pigmented patch indicates the presence of inflammation in the skin lesion. The melanin incontinence is caused by epidermal inflammation with infiltration of T lymphocytes, and the application of topical or systemic steroids predicts the reduction of the melanin incontinence. Therefore, distinguishing clearly between EDP and AD may contribute to the improving treatments for these pigmentary disorders.

The underlying pathomechanism of EDP or AD, as well as their etiology, remains unknown. Parasite infection [11], chemicals such as ammonium nitrate and barium sulfate, and environmental allergens are suspected causes [3]. An immunological response to any of these factors might define the extent of lesional inflammation of the skin based on the genetic profile, i.e., a strong inflammatory reaction against these factors might lead to EDP, whereas a mild reaction might lead to AD.

The macules or patches surrounded by elevated erythematous borders observed on the first visit of this patient to our clinic (fig. 1a) resulted in the diagnosis of EDP. However, after a follow-up of 4 months the skin lesions turned into brownish-grey to greyish-black, flat macules without an erythematous halo. Furthermore, during the 4-year follow-up period the elevated border was no longer observed in association with the pigmented macules, or patches, rendering the diagnosis of AD possible (fig. 1b). As described above, there is a clinical difference between EDP and AD. On the other hand, it was possible to make a dual diagnosis of EDP and AD in the case reported here. On the basis of these observations, we agree with the new classification of EDP and AD advocated by Zaynoun et al. [8] and propose that these pigmentary disorders be placed on the same spectrum. A detailed and rigorous description of the clinical features and appropriate classification will help to elucidate further the pathomechanism of EDP and AD.

\section{Statement of Ethics}

The authors have no ethical conflicts to disclose.

\section{Disclosure Statement}

The authors have no conflict of interest to declare.

\section{References}

1 Convit J, Kerdel-Vegas F, Rodríguez G: Erythema dyschromicum perstans: a hitherto undescribed skin disease. J Invest Dermatol 1961;36:457-462.

-2 Osswald SS, Proffer LH, Sartori CR: Erythema dyschromicum perstans: a case report and review. Cutis 2001;68:25-28.

-3 Schwartz RA: Erythema dyschromicum perstans: the continuing enigma of cinderella or ashy dermatosis. Int J Dermatol 2004;43:230-232.

4 Ramirez CO: The ashy dermatosis (erythema dyschromicum perstans): epidemiological study and report of 139 cases. Cutis 1967;3:244-247. 
Numata et al.: Erythema Dyschromicum Perstans: Identical to Ashy Dermatosis or Not?

5 Anstey AV: Disorders of skin colour; in Burns T, Breathnach S, Cox N, Griffiths C (eds): Rook's Textbook of Dermatology. Hoboken, Wiley-Blackwell, 2010, pp 1-59.

6 Lapeere H, Boone B, De Schepper S, Verhaeghe E, Van Geel M, Ongenae K, Van Geel N, Lambert J, Brochez L: Hypomelanoses and hypermelanoses; in Goldsmith LA, Katz SI, Gilchrest BA, Paller AS, Leffell DJ, Wolff K (eds): Fitzpatrick's Dermatology in General Medicine, ed 8. New York, The McGraw-Hill Companies, 2012, chapt 75.

7 Chang SE, Kim HW, Shin JM, Lee JH, Na JI, Roh MR, Lee GY, Ko JY: Clinical and histological aspect of erythema dyschromicum perstans in Korea: a review of 68 cases. J Dermatol 2015, Epub ahead of print.

8 Zaynoun S, Rubeiz N, Kibbi AG: Ashy dermatoses - a critical review of the literature and a proposed simplified clinical classification. Int J Dermatol 2008;47:542-544.

$\checkmark 9$ Muñoz C, Chang AL: A case of Cinderella: erythema dyschromicum perstans (ashy dermatosis or dermatosis cinecienta). Skinmed 2011;9:63-64.

10 Inoue S, Kikuchi I, Ishii Y, Idemori M: Erythema dyschromicum perstans. J Dermatol 1981;8:487-492.

11 Stevenson JR, Miura M: Erythema dyschromicum perstans (ashy dermatosis). Arch Dermatol 1966;94:196199.
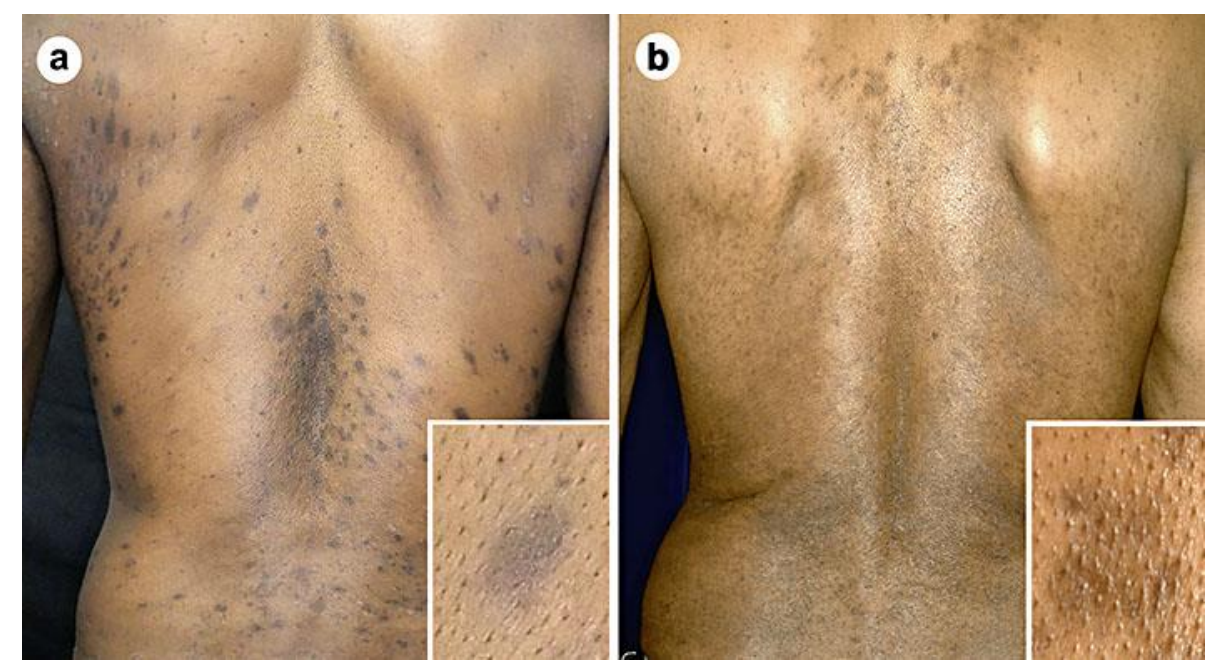

Fig. 1. a Pigmented macules and patches on the back. The skin lesions were arranged in a Christmas-tree pattern. Inset Pigmented macule with an elevated erythematous border. b Pigmented macules and patches on the back after 4 years' follow-up. Inset Pigmented macules without erythematous halo. 
Numata et al.: Erythema Dyschromicum Perstans: Identical to Ashy Dermatosis or Not?

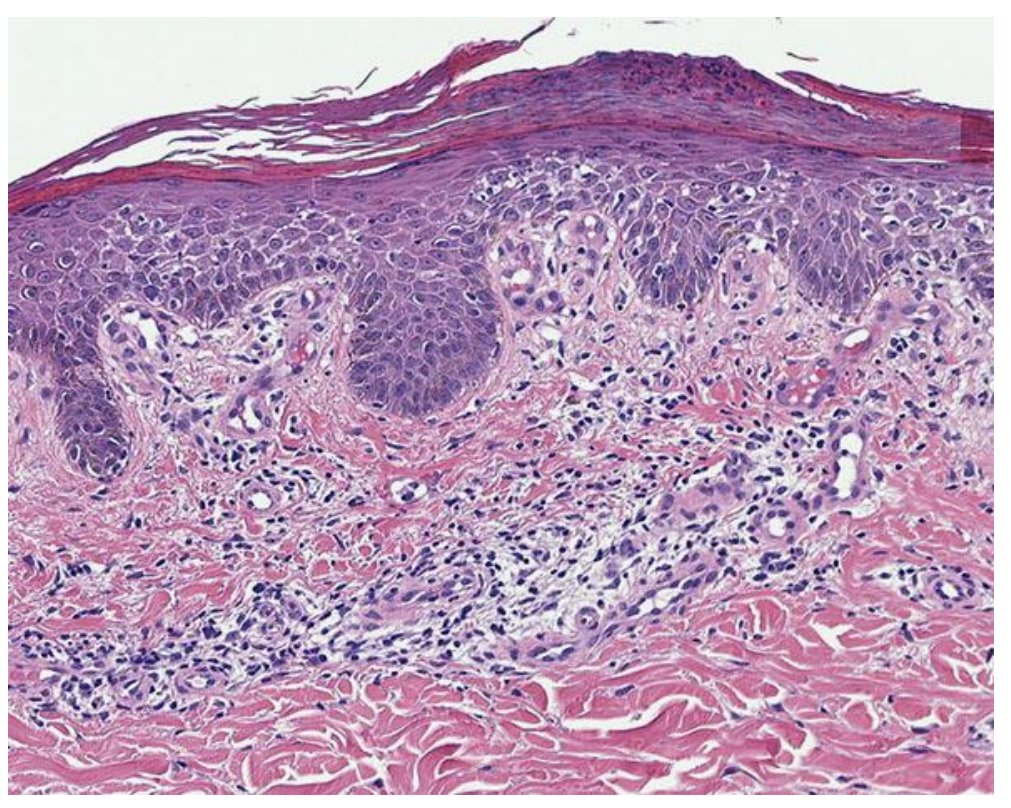

Fig. 2. The biopsy specimens taken from the erythematous border surrounding the pigmented macule on the right thigh revealed hyperkeratosis and parakeratosis in the stratum corneum, and infiltration of mononuclear cells into the epidermis. Partial disruption of the basement membrane as well as melanin incontinence and perivascular lymphocyte infiltration were observed in the dermis. Hematoxylin-eosin. Original magnification $\times 40$. 